\title{
Effect of ticagrelor with or without aspirin on vein graft outcome 1 year after on-pump and off-pump coronary artery bypass grafting
}

\author{
Yunpeng Zhu ${ }^{1 \#}$, Qing Xue ${ }^{2 \#}$, Minlu Zhang ${ }^{3}$, Junlong Hu ${ }^{4}$, Hao Liu ${ }^{5}$, Rui Wang ${ }^{6}$, Xiaowei Wang ${ }^{7}$ Lin Han $^{2}$, \\ Qiang Zhao'
}

${ }^{1}$ Department of Cardiovascular Surgery, Ruijin Hospital Shanghai Jiao Tong University School of Medicine, Shanghai, China; ${ }^{2}$ Department of Cardiovascular Surgery, Changhai Hospital of Shanghai, Shanghai, China; ${ }^{3}$ Department of Cancer Control and Prevention, Shanghai Municipal Center for Disease Control and Prevention, Shanghai, China; ${ }^{4}$ Department of Cardiovascular Surgery, Fuwai Central China Cardiovascular Hospital, Zhengzhou, China; ${ }^{5}$ Department of Cardiothoracic Surgery, Xinhua Hospital Shanghai Jiao Tong University School of Medicine, Shanghai, China; ${ }^{6}$ Department of Cardiovascular Surgery, Nanjing First Hospital, Nanjing, China; ${ }^{7}$ Department of Cardiovascular Surgery, Jiangsu Province Hospital, Nanjing, China

Contributions: (I) Conception and design: Y Zhu, Q Xue; (II) Administrative support: L Han, Q Zhao; (III) Provision of study materials or patients: Y Zhu, Q Xue, J Hu, H Liu, R Wang, X Wang, L Han, Q Zhao; (IV) Collection and assembly of data: Y Zhu, Q Xue, J Hu, H Liu, R Wang, X Wang; (V) Data analysis and interpretation: M Zhang, Y Zhu, Q Xue,; (VI) Manuscript writing: All authors; (VII) Final approval of manuscript: All authors.

"These authors contributed equally to this study.

Correspondence to: Qiang Zhao, MD. Department of Cardiovascular Surgery, Ruijin Hospital Shanghai Jiao Tong University School of Medicine, Shanghai, China. Email: zq11607@rjh.com.cn; Lin Han, MD. Department of Cardiovascular Surgery, Changhai Hospital of Shanghai, Shanghai, China. Email: sh_hanlin@163.com.

Background: In the present post hoc analysis of the DACAB trial, we evaluated the effects of ticagrelor with or without aspirin on 1-year vein graft outcomes after coronary artery bypass grafting (CABG) with and without cardiopulmonary bypass (CPB) (on-pump and off-pump).

Methods: The DACAB trial was a multicenter, randomized, open-label, parallel control study enrolling 500 patients with 1,460 vein grafts undergoing CABG. For current post-hoc study, all patients in the DACAB study were included in the analysis to compare the effects of different antiplatelet regimens under on/off pump. Patients were randomly assigned to 1 of 3 antiplatelet treatment regimens (ticagrelor plus aspirin, $\mathrm{T}+\mathrm{A}$; ticagrelor alone, $\mathrm{T}$; or aspirin alone, A) within 24 hours after CABG, and were stratified into on-pump and off-pump subgroups. The primary outcome was 1-year vein graft patency rate.

Results: Totally 121 patients underwent on-pump CABG (39 with 121 vein grafts in T + A, 36 with 101 vein grafts in $\mathrm{T}$, and 46 with 137 vein grafts in A) and 379 patients underwent off-pump CABG (129 with 336 vein grafts in $\mathrm{T}+\mathrm{A}, 130$ with 387 vein grafts in $\mathrm{T}$, and 120 with 348 vein grafts in $\mathrm{A})$. Compared with $\mathrm{A}$, $\mathrm{T}+\mathrm{A}$ showed a higher 1-year vein graft patency rate in both on-pump (adjusted OR for non-patency $=0.62$, 95\% CI: 0.16-2.45) and off-pump (adjusted OR for non-patency $=0.35,95 \%$ CI: $0.20-0.62$ ) subgroups, P interaction $=0.647$; whereas $\mathrm{T}$ did not in either on-pump (adjusted OR for non-patency $=0.92,95 \% \mathrm{CI}$ : $0.31-2.76$ ) or off-pump (adjusted OR for non-patency $=0.58,95 \%$ CI: 0.34-1.00) subgroups, P interaction $=0.430$.

Conclusions: In the DACAB trial, for patients underwent either on-pump or off-pump CABG, ticagrelor plus aspirin showed consistent benefit for achieving 1-year vein graft patency, with particular benefit being seen in the off-pump.

Keywords: Aspirin; cardiopulmonary bypass (CPB); coronary artery bypass grafting (CABG); dual antiplatelet therapy; ticagrelor; vein graft

Submitted Mar 05, 2020. Accepted for publication Jul 15, 2020.

doi: $10.21037 /$ jtd-20-1177

View this article at: http://dx.doi.org/10.21037/jtd-20-1177 


\section{Introduction}

Various factors are suggested to affect the outcomes of coronary artery bypass grafting (CABG), among which, the effects of cardiopulmonary bypass (CPB) has been extensively discussed for years but still controversial (1-3). Studies suggested that the activation and consumption of clotting factors and platelets in CABG with CPB (onpump $\mathrm{CABG}$ ) were associated with systemic inflammatory response and poor hemostasis compared with CABG without CPB (off-pump CABG) (1). On the other hand, the clotting disorders and platelet dysfunction with on-pump CABG may increase graft (especially vein graft) patency compared with off-pump surgery $(4,5)$. Therefore, although different guidelines recommend dual antiplatelet therapy (DAPT) after CABG to reduce major adverse cardiovascular events (MACEs) and preserve graft patency in patients with a history of acute coronary syndrome (ACS) $(1,6,7)$, the recommendation levels for off-pump (Class I) and on-pump (Class IIb) are different by considering that the use of $\mathrm{CPB}$ during CABG may affect the choices of therapeutic regimen and effects of antiplatelet therapy. In addition, beneficial effects of DAPT on graft patency was suggested not well demonstrated (8). These evidences indicate that the benefits of DAPT are not well established in both on-pump and offpump CABG.

Moreover, the recommended DAPT regimens after CABG are mostly based on findings on the use of clopidogrel plus aspirin. Ticagrelor, a reversible inhibitor of the P2Y12 receptor, in addition to aspirin, significantly reduced MACE in patients with ACS compared with clopidogrel (9). The CABG substudy from the PLATO trial showed that compared with clopidogrel, ticagrelor was associated with a substantial reduction in all-cause and cardiovascular mortality, without an excess risk of CABGrelated bleeding (10). The Different Antiplatelet Therapy Strategy After Coronary Artery Bypass Graft Surgery (DACAB) trial showed that ticagrelor plus aspirin resulted in a significant improvement in vein graft patency 1 year after CABG compared with aspirin alone (11). Compared with the practice in US and Europe, a higher proportion of patients (approximately 76\%) in this trial underwent offpump CABG, revealing the local practice in China, further on in East Asia. Here we examined the effects of ticagrelor with or without aspirin on vein graft patency 1 year after on-pump or off-pump CABG.

We present the following article in accordance with the
2010 CONSORT reporting checklist (available at http:// dx.doi.org/10.21037/jtd-20-1177).

\section{Methods}

\section{Background}

The DACAB trial was a multicenter, randomized, openlabel, parallel control study of 500 patients with 1,460 vein grafts undergoing CABG in China. Details about the study design, patients, and results have been published previously (11). The trial was conducted in accordance with the Declaration of Helsinki (as revised in 2013) and the Harmonized Tripartite Guideline for Good Clinical Practice from the International Conference on Harmonization. The trial protocol and all amendments were reviewed and approved by the independent Institutional Review Board responsible for each participating site. Written informed consent was obtained from all individual participants included in the study.

\section{Population}

For current post-hoc study, all patients in the DACAB study were included in the analysis. Briefly, patients aged 18-80 years with indications for CABG using vein grafts were eligible for the trial. Major exclusion criteria included urgent revascularization or other concomitant cardiac surgery, a need for dual antiplatelet or vitamin $\mathrm{K}$ antagonist therapy after CABG, and serious bleeding risk. Detailed inclusion and exclusion criteria are listed in Table S1.

Patients were randomly (in blocks of 3) assigned in a 1:1:1 ratio to receive ticagrelor (Brilinta, AstraZeneca) $90 \mathrm{mg}$ twice daily plus aspirin $100 \mathrm{mg}$ (Bayaspirin, Bayer) once daily, $\mathrm{T}+$ A regimen; ticagrelor $90 \mathrm{mg}$ twice daily, $\mathrm{T}$ regimen; or aspirin $100 \mathrm{mg}$ once daily, A regimen. Both on-pump and off-pump CABG was allowed in the trial and was selected according to the surgeons' decisions. Only surgeons with the experience of more than 100 off-pump cases annually were invited to participate in the trial. The vein graft was openly harvested. The patients started their allocated regimen within 24 hours after the surgery, and the median duration of study treatment was 1 year.

\section{Outcomes}

Consistent with the DACAB trial, the primary outcome 
of this post hoc analysis was the vein graft patency (stenosis $<50 \%$ ) rate 1 year after CABG. Vein grafts were assessed by multislice computed tomographic angiography or coronary angiography and interpreted by an independent Image Data Review Centre blinded to treatment allocation. Other cardiovascular outcomes includes: (I) the rate of MACE [defined as cardiovascular death, nonfatal myocardial infarction, and nonfatal stroke (12)] 1 year after the surgery; and (II) the rate of relief from angina pectoris evaluated using a questionnaire based on the Canadian Cardiovascular Society grade 1 year after the surgery.

For safety outcomes, the adverse events (AEs) and serious AEs (SAEs) were recorded for 1 year. Bleeding events were classified as those in the DACAB trial. The definitions of these outcomes have been previously reported (11).

\section{Statistical analysis}

This post-hoc analysis was to compare vein graft patency 1 year after CABG between patients receiving $\mathrm{T}+\mathrm{A}$ or $\mathrm{T}$ versus $\mathrm{A}$ in the on-pump and off-pump patients, respectively. The primary analysis was conducted on a per-graft basis according to the intention-to-treat (ITT) principle. The ITT population included all randomized patients. Missing data on graft outcome were handled as occlusion. One-year patency was also evaluated based on a per-patient basis. A per-patient analysis was performed in which patients were classified according to the graft with the worst degree of stenosis.

Differences in baseline characteristics between treatment groups after on-pump and off-pump CABG, as well as between on-pump and off-pump were compared using one-way analysis of variance or Kruskal-Wallis test for continuous variables and chi-square test or Fisher's exact test for categorical variables. Generalized estimating equations logistic model and multivariable logistic model were applied to estimate odds ratio (OR) and $95 \%$ confidence interval (CI) in per-graft and per-patient analysis, respectively. Outcome was defined as non-patency or occlusion when calculating OR. Confounders adjusted in the multivariable model included age; sex; medical history of hypertension, diabetes, and hyperlipidemia; SYNTAX score; target vessel distribution; and statin use 1 year after CABG. The potential modifying effect of pump status on different antiplatelet strategies was formally tested by including a multiplicative interaction term between pump status and antiplatelet treatment. All statistical analyses were carried out using SAS 9.4 (SAS Institute, NY, USA). Twosided $\mathrm{P}$ values $<0.05$ were considered statistically significant.

\section{Results}

\section{Baseline characteristics}

Among 500 patients with 1,460 vein grafts randomized in the trial, 121 patients with 359 vein grafts received on-pump CABG (39 patients with 121 vein grafts in $\mathrm{T}+\mathrm{A}$ regimen, 36 with 101 vein grafts in T regimen, and 46 with 137 vein grafts in A regimen) and 379 patients with 1,101 vein grafts received off-pump CABG (129 patients with 336 vein grafts in $\mathrm{T}+\mathrm{A}$ regimen, 130 with 387 vein grafts in $\mathrm{T}$ regimen, and 120 with 348 vein grafts in A regimen). The baseline characteristics were generally balanced among the three randomized antiplatelet treatment regimens in either onpump or off-pump subgroups, except that of the history of stroke, SYNTAX score, and angiotensin-converting enzyme inhibitor (ACEI)/angiotensin receptor blocker (ARB) use among the three antiplatelet treatment regimens in the offpump subgroup (Table S2). The comparisons on baseline demographics between on-pump and off-pump subgroups are detailed in Table $S 3$.

\section{One-year vein graft outcomes}

The graft-level analysis showed that the 1-year patency rate of vein graft was $91.7 \%$ in $\mathrm{T}+\mathrm{A}$ regimen compared with 83.2\% in A regimen for the on-pump subgroup (adjusted OR for non-patency $=0.62 ; 95 \%$ CI, $0.16-2.45$ ), and $87.7 \%$ in $\mathrm{T}+\mathrm{A}$ regimen compared with $73.9 \%$ in A regimen for the off-pump subgroup (adjusted OR for non-patency $=0.35 ; 95 \%$ CI, 0.20-0.62). As the interaction P between on-pump and off-pump subgroups while comparing $\mathrm{T}+$ A versus A was 0.647 , the result suggested that $T+A$ was associated with a higher 1-year patency rate of vein grafts compared with A in both on- and off-pump subgroups, which was consistent with the findings of overall trial. On the contrary, no significant differences were observed in the 1-year patency rate of vein grafts between $\mathrm{T}$ and $\mathrm{A}$ neither in on-pump (adjusted OR for non-patency $=0.92 ; 95 \% \mathrm{CI}$, 0.31-2.76) nor in off-pump (adjusted OR for non-patency $=0.58 ; 95 \% \mathrm{CI}, 0.34-1.00)$ subgroups $(\mathrm{P}$ interaction= 0.430$)$. The comparison of 1-year non-occlusion outcome were consistent with the patency outcome, where $\mathrm{T}+\mathrm{A}$ showed a higher non-occlusion rates compared with $\mathrm{A}$ in both offpump (OR $=0.38 ; 95 \%$ CI, 0.20-0.71) and on-pump (OR 


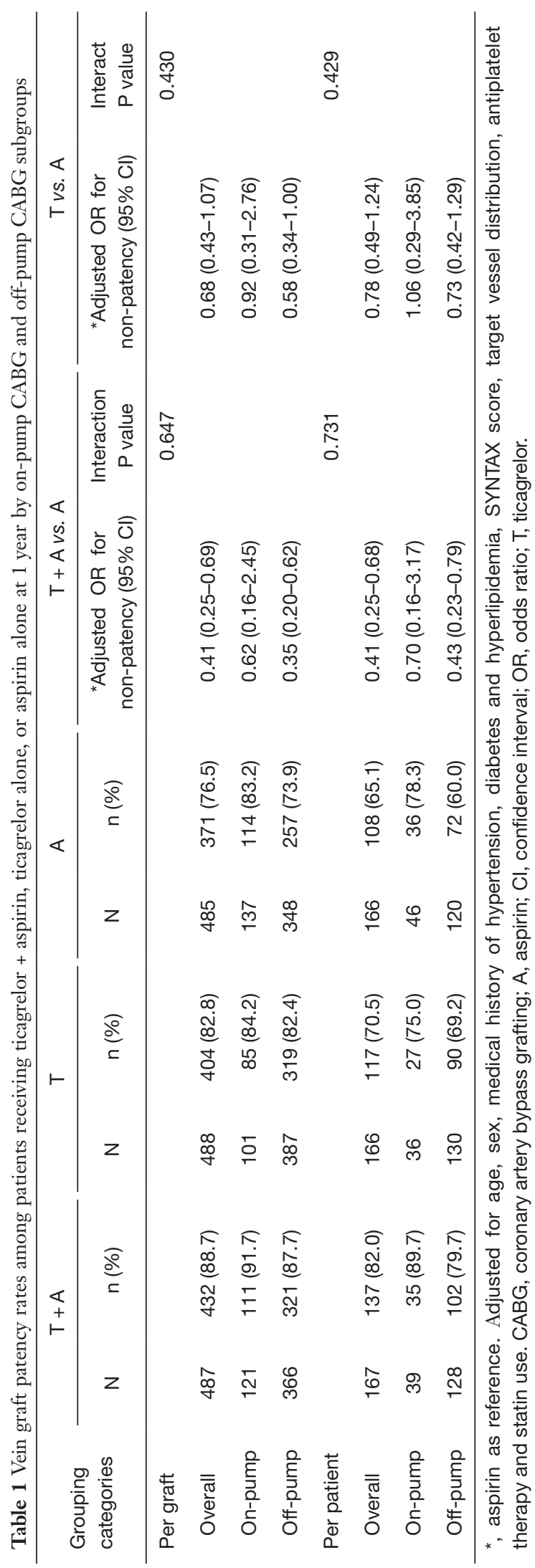

$=0.76 ; 95 \%$ CI, 0.18-3.12) groups with an interaction $\mathrm{P}=0.587$, and no significant differences were found in the comparisons between $\mathrm{T}$ and A. Similar results were seen in the patient-level analysis. Detailed vein graft patency and non-occlusion status in graft- and patient-level analyses are summarized in Tables 1 and 2. Comparisons between onpump and off-pump subgroups are shown in Table S4.

\section{Cardiovascular and bleeding outcomes}

Overall, the incidence of cardiovascular events, including the MACE and recurrent angina within 1 year after the surgery, were relatively low for all three regimens in both on- and off-pump subgroups. In statistical analysis, none of the rates of these events were significantly different among three regimens (Table 3). The bleeding events were similar for the three regimens in the on-pump subgroup; whereas in the off-pump subgroup, the non-CABG-related bleeding rate, particularly minimal bleeding, was significantly higher in $\mathrm{T}+\mathrm{A}$ compared with A (difference in the rate, 28\%; $95 \%$ CI, 18.2-37.9) (Table 4). Comparisons between the on- and off-pump subgroups regarding MACE, recurrent angina and bleeding events are shown in Tables $S 5$ and $S 6$.

\section{Other clinical AEs}

Some other clinical AEs, including renal dysfunction (creatinine $>200 \mu \mathrm{mol} / \mathrm{L}$ ), liver dysfunction (ALT/AST $>320 / 200 \mathrm{U} / \mathrm{L}$ ), pulmonary infections, and delayed incision healing, are listed in Tables $S 7$ and $S 8$.

\section{Discussion}

In this post-hoc analysis of the DACAB trial, we aimed to explore the effects of ticagrelor with or without aspirin on vein graft outcomes 1 year after CABG with or without $\mathrm{CPB}$. The results showed a consistent level of benefits of T + A over A alone for both on-pump and off-pump subgroups in increasing vein graft patency. This observation was consistent with the findings of overall DACAB trial, indicating that DAPT with a 12 -month $\mathrm{T}+\mathrm{A}$ regimen may be recommendable for all patients undergoing CABG with vein graft, regardless of the use of CPB.

Life-long aspirin is recognized as the gold standard of care after CABG (13). However, whether additional antiplatelet therapy with a $\mathrm{P} 2 \mathrm{Y} 12$ receptor antagonist is beneficial is still controversial $(12,14,15)$. Therefore, recent guidelines suggest that dual antiplatelet treatment 


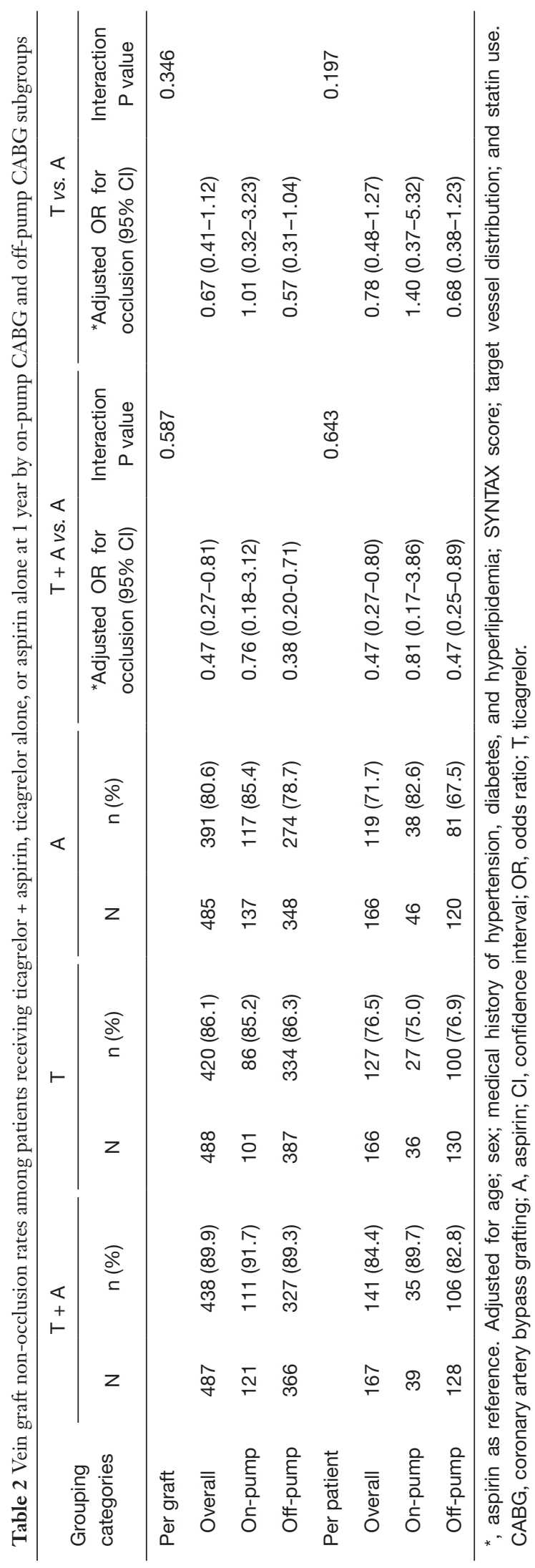

should be started after CABG in selected patients $(1,6,16)$. Whether the use of CPB during CABG influences the effects of DAPT needs further investigation. Regarding the effect of on-pump and off-pump CABG on patient outcomes, several studies suggested better graft outcomes in patients undergoing on-pump CABG. Sousa Uva et al. showed a lower graft patency rate for off-pump CABG, but the difference disappeared after controlling the heparin dose (17). Kim et al. demonstrated that the 1-year vein graft patency rate after off-pump CABG was low; they suggested that a specific perioperative anticoagulant therapy could be advisable (18). Gundry et al. reported the re-intervention rates of $30 \%$ in the off-pump group and $16 \%$ in the onpump group (19). On the contrary, some other studies showed similar outcomes for the two approaches $(2,3)$. Such contradictory results might be due to the complex prothrombotic response elicited by CABG. Therefore, antithrombosis therapy could be a key to enhancing graft patency, particularly for the hypercoagulated status in offpump CABG $(20,21)$.

Indeed, a few studies compared the different antiplatelet regimens after on-pump and off-pump CABG. To our knowledge, this post-hoc study is the first clinical report that examined whether the beneficial effect of $\mathrm{T}+\mathrm{A}$ based DAPT was consistent in patients with or without CPB. The results of this post-hoc study indicated that the $\mathrm{T}$ + A regimen was superior in achieving 1-year vein graft patency compared with A alone in both on-pump and offpump subgroups. On the other hand, clinical outcome was not statistically affected by DAPT, which might due to the insufficient event rates in DACAB trial. As limited analysis, including CURE and PLATO subgroup analysis $(22,23)$, has revealed the benefits of post-CABG DAPT, the potential risks, particularly intracranial bleeding and major gastrointestinal bleeding should be taken into consideration. Therefore, Costa et al. suggested that decision-maker should evaluate the individual patient's bleeding risk and consider the net clinical benefit from post-revascularization DAPT (24).

Regarding the higher early hypercoagulable state in offpump than in on-pump CABG, studies suggested that the short-term (1-year) vein graft patency was also affected, resulting in a lower patency rate in off-pump CABG $(18,21)$. However, more randomized trials indicated that the hypercoagulable state did not affect either very shortterm (30 days) or short-term (1 year) graft patency; they also showed that on-pump and off-pump CABG achieved similar patency (25). In the very short-term, vein graft 
Table 3 Cardiovascular events among patients receiving ticagrelor + aspirin, ticagrelor alone, or aspirin alone by on-pump CABG and off-pump CABG subgroups

\begin{tabular}{|c|c|c|c|c|c|c|c|}
\hline Events & \multicolumn{2}{|c|}{$\mathrm{T}+\mathrm{A}$} & \multicolumn{2}{|c|}{$\mathrm{T}$} & \multicolumn{2}{|c|}{ A } & $P$ value \\
\hline \multicolumn{8}{|c|}{ MACE in 1 year } \\
\hline On-pump & 39 & $1(2.6)$ & 36 & $1(2.6)$ & 46 & $3(6.5)$ & 0.625 \\
\hline Off-pump & 129 & $2(1.6)$ & 130 & $3(2.3)$ & 120 & $6(5.0)$ & 0.292 \\
\hline \multicolumn{8}{|l|}{ CV death } \\
\hline On-pump & 39 & $0(0.0)$ & 36 & $0(0.0)$ & 46 & $1(2.2)$ & \\
\hline Off-pump & 129 & $1(0.8)$ & 130 & $0(0.0)$ & 120 & $1(0.8)$ & \\
\hline \multicolumn{8}{|l|}{ Nonfatal MI } \\
\hline On-pump & 39 & $1(2.6)$ & 36 & $1(2.8)$ & 46 & $2(4.4)$ & \\
\hline On-pump & 39 & $0(0.0)$ & 36 & $0(0.0)$ & 46 & $0(0.0)$ & \\
\hline Off-pump & 129 & $0(0.0)$ & 130 & $2(1.5)$ & 120 & $4(3.3)$ & \\
\hline \multicolumn{8}{|c|}{ Recurrent angina in 1 year } \\
\hline On-pump & 39 & $1(2.6)$ & 36 & $0(0.0)$ & 46 & $2(4.4)$ & 0.776 \\
\hline Off-pump & 129 & $9(7.0)$ & 130 & $11(8.5)$ & 120 & $10(8.3)$ & 0.888 \\
\hline
\end{tabular}

CABG, coronary artery bypass grafting; A, aspirin; CV, cardiovascular; MACE, major adverse cardiovascular event; MI, myocardial infarction; T, ticagrelor.

failure might be triggered not only by the hypercoagulable state, but more by surgical accuracy, graft and target vessel quality, which could be hardly compensated by sophisticated antiplatelet strategy. In the short term or long term, the effects of antiplatelet strategy may play a greater role. The present study obtained similar results that 1-year patency rates were consistent in on- and off-pump CABG, suggesting a limited effect from the early coagulant state in most patients receiving antiplatelet therapy after CABG. Nevertheless, such conclusions should be confirmed in further trials with patients randomly allocated to on-pump and off-pump groups.

\section{Study limitations}

This post-hoc analysis had several limitations. First, as a non-prespecified subgroup analysis, the use of CPB was not randomized, but decided by surgeons instead, making the study inadequately powered to detect a statistically significant difference. Similarly, the insufficiency of statistical power, due to the relatively low event rate, to analyze the risk of bleeding and adverse events should be taken into consideration when interpreting the results that no significant differences were observed on major bleeding and MACEs among different antiplatelet strategy groups. Second, the graft outcome, which was the primary outcome in the present study, might not lead to clinical events. Although studies suggested a relationship between occluded grafts and subsequent outcomes, many graft failures are actually clinically silent (26). Also, the vein graft failure was not found to directly result in subsequent death or myocardial infarction (27).

\section{Conclusions}

In the present post-hoc analysis, the benefits of ticagrelor plus aspirin for achieving 1-year vein graft patency are consistent in both on-pump and off-pump subgroups, with particular benefit being seen in the off-pump subgroup. The results suggested that patients with vein graft could benefit from 1-year ticagrelor plus aspirin-based dual antiplatelet therapy regardless of the use of $\mathrm{CPB}$ during $\mathrm{CABG}$. 
Table 4 Bleeding events among patients receiving ticagrelor + aspirin, ticagrelor alone, or aspirin alone by on-pump CABG and off-pump CABG subgroups

\begin{tabular}{|c|c|c|c|c|c|c|c|c|c|}
\hline Events & \multicolumn{2}{|c|}{$T+A$} & \multicolumn{2}{|c|}{$\mathrm{T}$} & \multicolumn{2}{|c|}{ A } & \multicolumn{2}{|c|}{ Total } & $P$ value \\
\hline \multicolumn{10}{|c|}{ CABG-related } \\
\hline On-pump & 39 & $0(0.0)$ & 36 & $1(2.8)$ & 46 & $0(0.0)$ & 121 & $1(0.8)$ & 0.298 \\
\hline Off-pump & 129 & $1(0.8)$ & 130 & $0(0.0)$ & 120 & $0(0.0)$ & 379 & $1(0.3)$ & 0.657 \\
\hline On-pump & 39 & $3(7.7)$ & 36 & $2(5.6)$ & 46 & $4(8.7)$ & 121 & $9(7.4)$ & 0.912 \\
\hline Off-pump & 129 & $48(37.2)$ & 130 & 18 (13.9) & 120 & $11(9.2)$ & 379 & 77 (20.3) & $<0.001$ \\
\hline \multicolumn{10}{|l|}{ Major } \\
\hline On-pump & 39 & $0(0.0)$ & 36 & $0(0.0)$ & 46 & $0(0.0)$ & 121 & $0(0.0)$ & - \\
\hline On-pump & 39 & $0(0.0)$ & 36 & $0(0.0)$ & 46 & $1(2.2)$ & 121 & $1(0.8)$ & 1.000 \\
\hline Off-pump & 129 & $2(1.6)$ & 130 & $0(0.0)$ & 120 & $1(0.8)$ & 379 & $3(0.8)$ & 0.425 \\
\hline \multicolumn{10}{|l|}{ Minimal } \\
\hline On-pump & 39 & $3(7.7)$ & 36 & $2(5.6)$ & 46 & $3(6.5)$ & 121 & $8(6.6)$ & 1.000 \\
\hline Off-pump & 129 & 45 (34.9) & 130 & $17(13.1)$ & 120 & $10(8.3)$ & 379 & $72(19.0)$ & $<0.001$ \\
\hline \multicolumn{10}{|c|}{ *Overall major bleeding } \\
\hline On-pump & 39 & $0(0.0)$ & 36 & $1(2.8)$ & 46 & $0(0.0)$ & 121 & $1(0.8)$ & 0.298 \\
\hline Off-pump & 129 & $3(2.3)$ & 130 & $1(0.8)$ & 120 & $0(0.0)$ & 379 & $4(1.1)$ & 0.276 \\
\hline
\end{tabular}

*, overall major bleeding includes CABG-related bleeding and non-CABG-related major bleeding. CABG, coronary artery bypass grafting; A, aspirin; T, ticagrelor.

\section{Acknowledgments}

We thank Dr. Zheng Ke and MedSci for providing medical writing assistance. The statistical analysis was assisted by Department of Biostatistics, School of Public Health, Fudan University, Shanghai, China. All were compensated for their contributions.

Funding: The study was sponsored by Ruijin Hospital, Shanghai, China, and funded by AstraZeneca.

\section{Footnote}

Reporting Checklist: The authors have completed the CONSORT reporting checklist. Available at http://dx.doi. org/10.21037/jtd-20-1177

Data Sharing Statement: Available at http://dx.doi. org/10.21037/jtd-20-1177
Conflicts of Interest: All authors have completed the ICMJE uniform disclosure form (available at http://dx.doi. org/10.21037/jtd-20-1177). YZ has served as a speaker for AstraZeneca, Johnson \& Johnson, Novartis, and Sanofi, also as an investigator on clinical trials sponsored by AstraZeneca, Bayer, Novartis, and Sanofi. HL has served as a speaker for Pfizer. RW has served as a speaker for AstraZeneca and as an investigator on clinical trials sponsored by Bayer. XW has served as a speaker for AstraZeneca and Johnson \& Johnson. LH has served as a speaker for Medtronic. QZ has served as a speaker for AstraZeneca, Johnson \& Johnson, and Medtronic, and also been an investigator on clinical trials sponsored by AstraZeneca, Bayer, Novartis, and Sanofi. The other authors have no conflicts of interest to declare.

Ethical Statement: The authors are accountable for all 
aspects of the work in ensuring that questions related to the accuracy or integrity of any part of the work are appropriately investigated and resolved. The trial was conducted in accordance with the Declaration of Helsinki (as revised in 2013) and the Harmonized Tripartite Guideline for Good Clinical Practice from the International Conference on Harmonization. The trial protocol and all amendments were reviewed and approved by the independent Institutional Review Board responsible for each participating site. Written informed consent was obtained from all individual participants included in the study.

Open Access Statement: This is an Open Access article distributed in accordance with the Creative Commons Attribution-NonCommercial-NoDerivs 4.0 International License (CC BY-NC-ND 4.0), which permits the noncommercial replication and distribution of the article with the strict proviso that no changes or edits are made and the original work is properly cited (including links to both the formal publication through the relevant DOI and the license). See: https://creativecommons.org/licenses/by-nc-nd/4.0/.

\section{References}

1. Kulik A, Ruel M, Jneid H, et al. Secondary prevention after coronary artery bypass graft surgery: a scientific statement from the American Heart Association. Circulation 2015;131:927-64.

2. Lamy A, Devereaux PJ, Prabhakaran D, et al. Five-Year Outcomes after Off-Pump or On-Pump Coronary-Artery Bypass Grafting. N Engl J Med 2016;375:2359-68.

3. Puskas JD, Williams WH, O'Donnell R, et al. Offpump and on-pump coronary artery bypass grafting are associated with similar graft patency, myocardial ischemia, and freedom from reintervention: long-term follow-up of a randomized trial. Ann Thorac Surg 2011;91:1836-42; discussion 1842-3.

4. Møller CH, Penninga L, Wetterslev J, et al. Off-pump versus on-pump coronary artery bypass grafting for ischaemic heart disease. Cochrane Database Syst Rev 2012;(3):CD007224.

5. Khan NE, De Souza A, Mister R, et al. A randomized comparison of off-pump and on-pump multivessel coronary-artery bypass surgery. $\mathrm{N}$ Engl J Med 2004;350:21-8.

6. Valgimigli M, Bueno H, Byrne RA, et al. 2017 ESC focused update on dual antiplatelet therapy in coronary artery disease developed in collaboration with EACTS. Eur J Cardiothorac Surg 2018;53:34-78.

7. Neumann FJ, Sousa-Uva M, Ahlsson A, et al. 2018 ESC/ EACTS Guidelines on myocardial revascularization. EuroIntervention 2019;14:1435-534.

8. de Leon N, Jackevicius CA. Use of aspirin and clopidogrel after coronary artery bypass graft surgery. Ann Pharmacother 2012;46:678-87.

9. Wallentin L, Becker RC, Budaj A, et al. Ticagrelor versus clopidogrel in patients with acute coronary syndromes. $\mathrm{N}$ Engl J Med 2009;361:1045-57.

10. Brilakis ES, Held C, Meier B, et al. Effect of ticagrelor on the outcomes of patients with prior coronary artery bypass graft surgery: insights from the PLATelet inhibition and patient outcomes (PLATO) trial. Am Heart J 2013;166:474-80.

11. Zhao Q, Zhu Y, Xu Z, et al. Effect of ticagrelor plus aspirin, ticagrelor alone, or aspirin alone on saphenous vein graft patency 1 year after coronary artery bypass grafting: a randomized clinical trial. JAMA 2018;319:1677-86.

12. Chakos A, Jbara D, Singh K, et al. Network meta-analysis of antiplatelet therapy following coronary artery bypass grafting (CABG): none versus one versus two antiplatelet agents. Ann Cardiothorac Surg 2018;7:577-85.

13. Hillis LD, Smith PK, Anderson JL, et al. 2011 ACCF/ AHA Guideline for Coronary Artery Bypass Graft Surgery. A report of the American College of Cardiology Foundation/American Heart Association Task Force on Practice Guidelines. Developed in collaboration with the American Association for Thoracic Surgery, Society of Cardiovascular Anesthesiologists, and Society of Thoracic Surgeons. J Am Coll Cardiol 2011;58:e123-210.

14. Kulik A, Le May MR, Voisine P, et al. Aspirin plus clopidogrel versus aspirin alone after coronary artery bypass grafting: the clopidogrel after surgery for coronary artery disease (CASCADE) Trial. Circulation 2010;122:2680-7.

15. Gao G, Zheng Z, Pi Y, et al. Aspirin plus clopidogrel therapy increases early venous graft patency after coronary artery bypass surgery a single-center, randomized, controlled trial. J Am Coll Cardiol 2010;56:1639-43.

16. Ibanez B, James S, Agewall S, et al. 2017 ESC Guidelines for the management of acute myocardial infarction in patients presenting with ST-segment elevation: The Task Force for the management of acute myocardial infarction in patients presenting with ST-segment elevation of the European Society of Cardiology (ESC). Eur Heart J 


$$
\text { 2018;39:119-77. }
$$

17. Sousa Uva M, Cavaco S, Oliveira AG, et al. Early graft patency after off-pump and on-pump coronary bypass surgery: a prospective randomized study. Eur Heart J 2010;31:2492-9.

18. Kim KB, Lim C, Lee C, et al. Off-pump coronary artery bypass may decrease the patency of saphenous vein grafts. Ann Thorac Surg 2001;72:S1033-7.

19. Gundry SR, Romano MA, Shattuck OH, et al. Seven-year follow-up of coronary artery bypasses performed with and without cardiopulmonary bypass. J Thorac Cardiovasc Surg 1998;115:1273-7; discussion 1277-8.

20. Cavalca V, Rocca B, Veglia F, et al. On-pump Cardiac Surgery Enhances Platelet Renewal and Impairs Aspirin Pharmacodynamics: Effects of Improved Dosing Regimens. Clin Pharmacol Ther 2017;102:849-58.

21. Bednar F, Osmancik P, Vanek T, et al. Platelet activity and aspirin efficacy after off-pump compared with onpump coronary artery bypass surgery: results from the prospective randomized trial PRAGUE 11-Coronary Artery Bypass and REactivity of Thrombocytes (CABARET). J Thorac Cardiovasc Surg 2008;136:1054-60.

22. Fox KA, Mehta SR, Peters R, et al. Benefits and risks of the combination of clopidogrel and aspirin in patients undergoing surgical revascularization for non-ST-elevation acute coronary syndrome: the Clopidogrel in Unstable angina to prevent Recurrent ischemic Events (CURE) Trial. Circulation 2004;110:1202-8.

23. Held C, Asenblad N, Bassand JP, et al. Ticagrelor versus clopidogrel in patients with acute coronary syndromes undergoing coronary artery bypass surgery: results from the PLATO (Platelet Inhibition and Patient Outcomes) trial. J Am Coll Cardiol 2011;57:672-84.

24. Costa F, Van Klaveren D, Feres F, et al. Dual Antiplatelet Therapy Duration Based on Ischemic and Bleeding Risks After Coronary Stenting. J Am Coll Cardiol 2019;73:741-54.

25. Puskas JD, Williams WH, Mahoney EM, et al. Off-pump vs conventional coronary artery bypass grafting: early and 1-year graft patency, cost, and quality-of-life outcomes: a randomized trial. JAMA 2004;291:1841-9.

26. Harskamp RE, Alexander JH, Schulte PJ, et al. Vein graft preservation solutions, patency, and outcomes after coronary artery bypass graft surgery: follow-up from the PREVENT IV randomized clinical trial. JAMA Surg 2014;149:798-805.

27. Lopes RD, Mehta RH, Hafley GE, et al. Relationship between vein graft failure and subsequent clinical outcomes after coronary artery bypass surgery. Circulation 2012;125:749-56.
Cite this article as: Zhu Y, Xue Q, Zhang M, Hu J, Liu H, Wang R, Wang X, Han L, Zhao Q. Effect of ticagrelor with or without aspirin on vein graft outcome 1 year after on-pump and off-pump coronary artery bypass grafting. $J$ Thorac Dis 2020;12(9):4915-4923. doi: 10.21037/jtd-20-1177 


\section{Supplementary}

Table S1 Inclusion and exclusion criteria

Inclusion criteria

1. Female and male patients aged $18-80$ years

2. Patients are able to provide written informed consent

3. Informed consent prior to any study specific procedures

4. Indication for CABG surgery:

$\geq 3$ coronary vessels (partially) occlusion, or

Left major coronary vessel stenosis, or

Two coronary vessels (partially) occlusion and impaired left ventricular function

Exclusion criteria

1. Cardiogenic shock, hemodynamic instability

2. Need for urgent revascularization within 5 days from presentation

3. Single vessel disease

4. Two vessel disease with normal left ventricular function (>50\%)

5. Need for concomitant other cardiac surgery (e.g., valve replacement)

6. Need for dual antiplatelet treatment for the patients undergoing CABG after acute coronary syndrome

7. Contraindication for aspirin and ticagrelor use (e.g., known allergy)

8. History of bleeding diathesis within 3 months prior presentation

9. History of significant Gl bleed within 1 year prior to presentation

10. History of peptic ulcer without Gl bleeding in past 3 years

11. History of intracranial hemorrhage

12. History of moderate to severe liver impairment

13.Patient requiring dialysis

14.Patient with an increased risk of bradycardia (e.g., patients without a pacemaker who have sick sinus syndrome, 2nd or 3rd degree AV block or bradycardia-related syncope)

15.Need vitamin $\mathrm{K}$ antagonist therapy after CABG (e.g., persistent atrial fibrillation, mechanical heart valves)

16.Known, clinically important thrombocytopenia (i.e., $<100 \times 10^{9} / \mathrm{L}$ )

17.Known, clinically important anemia (i.e., $<100 \mathrm{~g} / \mathrm{L}$ )

18.Participation in another investigational drug or device study in the last 30 days

19.Pregnant or lactating female patients. Premenopausal women are required to use 2 methods of reliable contraception, one of which must barrier method

20. Concomitant oral or intravenous therapy with strong CYP3A4 inhibitors, CYP3A4 substrates with narrow therapeutic indices, or strong CYP3A4 inducers which cannot be stopped for the course of the study (strong inhibitors include ketoconazole, itraconazole, voriconazole, telithromycin, clarithromycin, nefazodone, ritonavir, saquinavir, nelfinavir, indinavir, atazanavir, and $>1$ liter/day of grapefruit juice. Substrates with a narrow therapeutic index include cyclosporine, and quinidine Strong inducers include rifampin, phenytoin, and carbamazepine)

21.Active cancer

22. Life expectancy $<12$ months

23. Indication for major surgery (e.g., cancer treatment, carotid surgery, cerebral surgery, major vascular surgery)

CABG, coronary artery bypass grafting. 


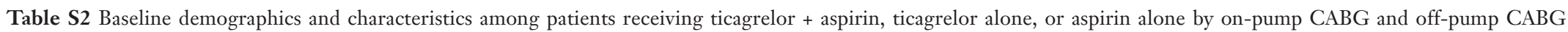
subgroups

\begin{tabular}{|c|c|c|c|c|c|c|c|c|}
\hline \multirow{2}{*}{ Patient characteristics } & \multicolumn{4}{|c|}{ On-pump } & \multicolumn{4}{|c|}{ Off-pump } \\
\hline & $T+A(n=39)$ & $T(n=36)$ & $A(n=46)$ & $P$ value & $T+A(n=129)$ & $T(n=130)$ & $A(n=120)$ & $P$ value \\
\hline Age (SD), y & $61.0(9.2)$ & $61.9(8.5)$ & $62.8(9.2)$ & $0.677^{\star}$ & $64.2(7.7)$ & $63.7(8.2)$ & $64.5(7.6)$ & $0.753^{\star}$ \\
\hline Male, n (\%) & $34(87.2)$ & $30(83.3)$ & $38(82.6)$ & $0.832^{*}$ & $100(77.5)$ & $104(80.0)$ & $103(85.8)$ & $0.232^{*}$ \\
\hline \multicolumn{9}{|l|}{ Clinical status, n (\%) } \\
\hline Stable angina & $7(18.0)$ & $8(22.2)$ & $9(19.6)$ & $0.932^{\star \star}$ & $48(37.2)$ & $55(42.3)$ & $41(34.2)$ & $0.363^{\star \star}$ \\
\hline Unstable angina & $30(76.9)$ & $25(69.4)$ & $35(76.1)$ & & $78(60.5)$ & $74(56.9)$ & $74(61.7)$ & \\
\hline NSTEMI & $2(5.1)$ & $3(8.3)$ & $2(4.4)$ & & $3(2.3)$ & $1(0.8)$ & $5(4.2)$ & \\
\hline History of myocardial infarction, n (\%) & $11(28.2)$ & $12(33.3)$ & $9(19.6)$ & $0.357^{*}$ & $42(32.6)$ & $48(36.9)$ & $34(28.3)$ & $0.351^{*}$ \\
\hline \multicolumn{9}{|l|}{ Heart function (NYHA), n (\%) } \\
\hline III & $19(48.7)$ & $17(47.2)$ & $20(43.5)$ & $0.950^{\star \star}$ & $50(38.8)$ & $48(36.9)$ & $42(35.0)$ & $0.809^{* *}$ \\
\hline IV & $1(2.6)$ & $0(0.0)$ & $1(2.2)$ & & $0(0.0)$ & $0(0.0)$ & $1(0.83)$ & \\
\hline \multicolumn{9}{|l|}{ Medical history, n (\%) } \\
\hline Hypertension & $28(71.8)$ & $25(69.4)$ & $32(69.6)$ & $0.968^{*}$ & $99(76.7)$ & $97(74.6)$ & 88 (73.3) & $0.821^{*}$ \\
\hline Hyperlipidemia (or LDL-C $\geq 1.8$ mmol/L) & $34(87.2)$ & $28(77.8)$ & $34(73.9)$ & $0.310^{*}$ & $87(67.4)$ & $96(73.9)$ & $85(70.8)$ & $0.526^{\star}$ \\
\hline Diabetes mellitus (or $\mathrm{HbA} 1 \mathrm{c} \geq 6.5 \%$ ) & $17(43.6)$ & $15(41.7)$ & $19(41.3)$ & $0.975^{\star}$ & $58(45.0)$ & $60(46.2)$ & $48(40.0)$ & $0.587^{*}$ \\
\hline Peripheral vascular disease & $4(10.3)$ & $2(5.6)$ & $3(6.5)$ & $0.753^{\star \star}$ & $22(17.1)$ & 25 (19.2) & $26(21.7)$ & $0.654^{*}$ \\
\hline Stroke & $3(7.7)$ & $4(11.1)$ & $4(8.7)$ & $0.855^{\star \star}$ & $23(17.8)$ & $9(6.9)$ & $18(15.0)$ & $0.027^{*}$ \\
\hline Smoking & $22(56.4)$ & $16(44.4)$ & $20(43.5)$ & $0.435^{\star}$ & $63(48.8)$ & $58(44.6)$ & $67(55.8)$ & $0.203^{\star}$ \\
\hline LVEF, median (Q1, Q3), \% & $59(52.0,63.0)$ & $60.5(56.0,63.0)$ & $61.5(55.0,64.0)$ & $0.136^{\star}$ & $63(57.0,68.0)$ & $62(58.0,67.0)$ & $64(57.5,68.0)$ & $0.823^{*}$ \\
\hline SYNTAX score, n (\%) & & & & $0.317^{*}$ & & & & $0.030^{\star}$ \\
\hline Low (0-22) & $5(12.8)$ & $9(25.0)$ & $9(19.6)$ & & $13(10.1)$ & $12(9.2)$ & $22(18.3)$ & \\
\hline Intermediate [23-32] & $19(48.7)$ & $15(41.7)$ & $27(58.7)$ & & $74(57.4)$ & $68(52.3)$ & $71(59.2)$ & \\
\hline High $(\geq 33)$ & $15(38.5)$ & $12(33.3)$ & $10(21.7)$ & & $42(32.6)$ & $50(38.5)$ & $27(22.5)$ & \\
\hline EuroSCORE, n (\%) & & & & $0.681^{*}$ & & & & $0.097^{*}$ \\
\hline Low (0-2) & $9(23.1)$ & $5(13.9)$ & $12(26.1)$ & & $62(48.1)$ & $58(44.6)$ & $52(43.3)$ & \\
\hline Medium [3-5] & $20(51.3)$ & $23(63.9)$ & $24(52.2)$ & & $45(34.9)$ & $59(45.4)$ & $58(48.3)$ & \\
\hline $\operatorname{High}(\geq 6)$ & $10(25.6)$ & $8(22.2)$ & $10(21.7)$ & & $22(17.1)$ & $13(10.0)$ & $10(8.3)$ & \\
\hline \multicolumn{9}{|l|}{ Baseline medication, n (\%) } \\
\hline Aspirin & $3(10.0)$ & $2(6.9)$ & $3(8.8)$ & $1.000^{\star \star}$ & $35(28.9)$ & $35(28.7)$ & $31(28.4)$ & $0.997^{*}$ \\
\hline$\beta$-blocker & $31(79.5)$ & $25(69.4)$ & $33(71.7)$ & $0.578^{*}$ & $122(94.6)$ & $124(95.4)$ & $116(96.7)$ & $0.725^{\star}$ \\
\hline ACEI/ARB & $18(46.2)$ & $12(33.3)$ & $21(45.7)$ & $0.441^{*}$ & $69(53.5)$ & $86(66.2)$ & $83(69.2)$ & $0.024^{*}$ \\
\hline Statins & $34(87.2)$ & $30(83.3)$ & $40(87.0)$ & $0.864^{*}$ & $123(95.4)$ & $125(96.2)$ & $117(97.5)$ & $0.703^{\star \star}$ \\
\hline Proton pump inhibitor & $8(20.5)$ & $9(25.0)$ & $12(26.1)$ & $0.823^{*}$ & $96(74.4)$ & 99 (76.2) & $93(77.5)$ & $0.849^{\star}$ \\
\hline Total grafts, $n$ & 156 & 137 & 178 & & 475 & 499 & 446 & \\
\hline Graft type, n (\%) & & & & $0.440^{\star *}$ & & & & $0.836^{* \star}$ \\
\hline IMA & $35(22.4)$ & $33(24.1)$ & $38(21.4)$ & & $106(22.3)$ & $111(22.2)$ & $95(21.3)$ & \\
\hline RA & $0(0.0)$ & $3(2.2)$ & $3(1.7)$ & & $3(0.6)$ & $1(0.2)$ & $3(0.7)$ & \\
\hline SVG & $121(77.6)$ & $101(73.7)$ & $137(77.0)$ & & $366(77.1)$ & 387 (77.6) & $348(78.0)$ & \\
\hline
\end{tabular}

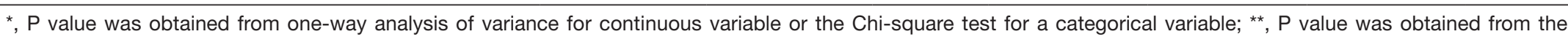

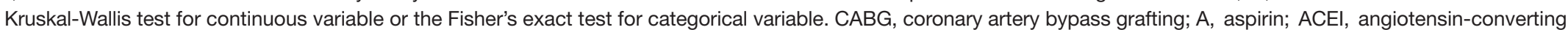

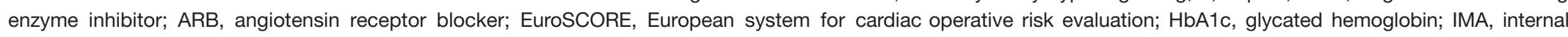

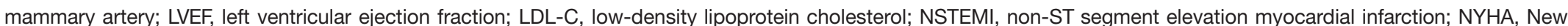

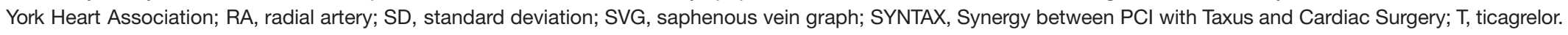


Table S3 Baseline demographics and characteristics between patients receiving on-pump and off-pump CABG

\begin{tabular}{|c|c|c|c|c|}
\hline Characteristics & On-pump (n=121) & Off-pump (n=379) & Overall $(n=500)$ & $P$ value ${ }^{\star}$ \\
\hline Age, mean (SD), y & $62.0(9.0)$ & $64.1(7.8)$ & $63.6(8.2)$ & 0.010 \\
\hline \multicolumn{5}{|l|}{ Age stratified } \\
\hline$\leq 60 \mathrm{y}$ & $51(42.2)$ & $114(30.1)$ & $165(33.0)$ & \multirow[t]{3}{*}{0.044} \\
\hline $61-75 y$ & $60(49.6)$ & $233(61.5)$ & $293(58.6)$ & \\
\hline$>75 \mathrm{y}$ & $10(8.3)$ & $32(8.4)$ & $42(8.4)$ & \\
\hline Male gender, No. (\%) & $102(84.3)$ & $307(81.0)$ & $409(81.8)$ & 0.414 \\
\hline \multicolumn{5}{|l|}{ Clinical status, No. (\%) } \\
\hline Stable angina & $24(19.8)$ & $144(38.0)$ & $168(33.6)$ & \multirow[t]{3}{*}{$<0.001$} \\
\hline Unstable angina & $90(74.4)$ & $226(59.6)$ & $316(63.2)$ & \\
\hline NSTEMI & $7(5.8)$ & $9(2.4)$ & $16(3.2)$ & \\
\hline History of myocardial infarction, №. (\%) & $32(26.5)$ & $124(32.7)$ & $156(31.2)$ & 0.195 \\
\hline \multicolumn{5}{|l|}{ Time since onset of myocardial infarction } \\
\hline$<21 \mathrm{~d}$ & $8(6.6)$ & $10(2.6)$ & $18(3.6)$ & \multirow[t]{3}{*}{$0.041^{\star *}$} \\
\hline $21-90 d$ & $3(2.5)$ & $11(2.9)$ & $14(2.8)$ & \\
\hline$>90 \mathrm{~d}$ & $21(17.4)$ & $103(27.2)$ & $124(24.8)$ & \\
\hline \multicolumn{5}{|l|}{ Angina (CCS), No. (\%) } \\
\hline III & 89 (73.6) & $208(54.9)$ & $297(59.4)$ & \multirow[t]{2}{*}{$<0.001$} \\
\hline IV & $6(5.0)$ & $10(2.6)$ & $16(3.2)$ & \\
\hline Heart function (NYHA), No. (\%) & & & & \\
\hline IIII & $56(46.3)$ & $140(36.9)$ & $196(39.2)$ & $0.033^{\star \star}$ \\
\hline IV & $2(1.7)$ & $1(0.3)$ & $3(0.6)$ & \\
\hline Medical history, No. (\%) & & & & \\
\hline Hypertension & $85(70.3)$ & $284(74.9)$ & $369(73.8)$ & 0.307 \\
\hline Hyperlipidemia (or LDL-C $\geq 1.8 \mathrm{mmol} / \mathrm{L}$ ) & $96(79.3)$ & $268(70.7)$ & $364(72.8)$ & 0.063 \\
\hline Diabetes mellitus (or $\mathrm{HbA} 1 \mathrm{c} \geq 6.5 \%$ ) & 51 (42.2) & $166(43.8)$ & $217(43.4)$ & 0.750 \\
\hline Peripheral vascular disease & $9(7.4)$ & $73(19.3)$ & $82(16.4)$ & 0.002 \\
\hline Cerebrovascular accident & $11(9.1)$ & $50(13.2)$ & $61(12.2)$ & 0.230 \\
\hline Peptic ulcer disease & $2(1.7)$ & $9(2.4)$ & $11(2.2)$ & $1.000^{* *}$ \\
\hline Chronic kidney disease & $2(1.7)$ & $7(1.9)$ & $9(1.8)$ & $1.000^{* *}$ \\
\hline Smoking & $58(47.9)$ & $188(49.6)$ & $246(49.2)$ & 0.749 \\
\hline COPD & $5(4.1)$ & $34(9.0)$ & $39(7.8)$ & 0.084 \\
\hline LVEDD, median (Q1, Q3), mm & $46.0(44.0,52.0)$ & $50.0(47.0,53.0)$ & $49.0(46.0,53.0)$ & 0.003 \\
\hline LVEF, median (Q1, Q3), \% & $60.0(55.0,63.0)$ & $63.0(58.0,68.0)$ & $62.0(57.0,67.0)$ & $<0.001$ \\
\hline LVEF, N (\%) & & & & \\
\hline $30-50 \%$ & $16(13.2)$ & $39(10.3)$ & $55(11.0)$ & 0.374 \\
\hline$>50 \%$ & $105(86.8)$ & $339(89.7)$ & $444(89.0)$ & \\
\hline SYNTAX score, No. (\%) & & & & \\
\hline Low (0-22) & $23(19.0)$ & $47(12.4)$ & $70(14.0)$ & 0.179 \\
\hline Intermediate [23-32] & $61(50.4)$ & $213(56.2)$ & $274(54.8)$ & \\
\hline High ( $(\geq 33)$ & $37(30.6)$ & $119(31.4)$ & $156(31.2)$ & \\
\hline EurosCORE, No. (\%) & & & & \\
\hline Low (0-2) & $26(21.5)$ & $172(45.4)$ & $198(39.6)$ & $<0.001$ \\
\hline Medium [3-5] & $67(55.4)$ & $162(42.7)$ & $229(45.8)$ & \\
\hline $\operatorname{High}(\geq 6)$ & $28(23.1)$ & $45(11.9)$ & $73(14.6)$ & \\
\hline Medication use, baseline, No. (\%) & & & & \\
\hline Aspirin & $8(8.6)$ & $101(28.7)$ & $109(24.5)$ & $<0.001$ \\
\hline$\beta$-blocker & $89(73.6)$ & $362(95.5)$ & $451(90.2)$ & $<0.001$ \\
\hline ACEI/ARB & $51(42.2)$ & $238(62.8)$ & $289(57.8)$ & $<0.001$ \\
\hline Statins & $104(86.0)$ & $365(96.3)$ & $469(93.8)$ & $<0.001$ \\
\hline Proton pump inhibitor & $29(24.0)$ & $288(76.0)$ & $317(63.4)$ & $<0.001$ \\
\hline Medication use, 7 days, No. (\%) & & & & \\
\hline$\beta$-blocker & $113(93.4)$ & $374(98.7)$ & $487(97.4)$ & $0.004^{* *}$ \\
\hline ACEI/ARB & $47(38.8)$ & $211(55.7)$ & $258(51.6)$ & 0.001 \\
\hline Statins & $107(88.4)$ & $374(98.7)$ & $481(96.2)$ & $<0.001^{* *}$ \\
\hline Proton pump inhibitor & $118(97.5)$ & $347(91.6)$ & $465(93.0)$ & 0.025 \\
\hline Medication use, 1 year, No. (\%) & & & & \\
\hline$\beta$-blocker & $108(89.3)$ & $361(95.3)$ & $469(93.8)$ & 0.017 \\
\hline ACEI/ARB & $34(28.1)$ & $206(54.4)$ & $240(48.0)$ & $<0.001$ \\
\hline Statins & $115(95.0)$ & $364(96.0)$ & $479(95.8)$ & 0.633 \\
\hline Proton pump inhibitor & $0(0.0)$ & $9(2.4)$ & $9(1.8)$ & 0.122 \\
\hline Surgical procedure characteristics & & & & \\
\hline Total grafts, No. & 471 & 1420 & 1891 & \\
\hline Graft type, No. (\%) & & & & 0.196 \\
\hline IMA & $106(22.5)$ & $312(22.0)$ & $418(22.1)$ & \\
\hline LAD & $106(100.0)$ & $310(99.4)$ & $416(99.5)$ & 1.000 \\
\hline LCX & $0(0.0)$ & $2(0.6)$ & $2(0.5)$ & \\
\hline RA & $6(1.3)$ & $7(0.5)$ & $13(0.7)$ & \\
\hline LAD & $0(0.0)$ & $2(28.6)$ & $2(15.4)$ & 0.462 \\
\hline LCX & $6(100.0)$ & $5(71.4)$ & $11(84.6)$ & \\
\hline SVG & $359(76.2)$ & $1101(77.5)$ & $1460(77.2)$ & \\
\hline LAD & $95(26.5)$ & $320(29.1)$ & $415(28.4)$ & 0.476 \\
\hline LCX & $143(39.8)$ & $402(36.5)$ & $545(37.3)$ & \\
\hline RCA & $121(33.7)$ & $379(34.4)$ & $500(34.3)$ & \\
\hline Intervention & & & & \\
\hline$T+A$ & $39(32.2)$ & $129(34.0)$ & $168(33.6)$ & 0.412 \\
\hline Talone & $36(29.8)$ & $130(34.3)$ & $166(33.2)$ & \\
\hline A alone & $46(38.0)$ & $120(31.7)$ & $166(33.2)$ & \\
\hline
\end{tabular}


Table S4 Vein graft patency and non-occlusion rates at 1 year between patients receiving on-pump and off-pump CABG

\begin{tabular}{|c|c|c|c|c|c|c|c|}
\hline $\begin{array}{l}\text { Grouping } \\
\text { categories }\end{array}$ & $\mathrm{N}$ & \multicolumn{3}{|c|}{ Patency } & \multicolumn{3}{|c|}{ Non-occlusion } \\
\hline On-pump & 359 & 310 (86.4) & & & $314(87.5)$ & & \\
\hline Off-pump & 1,101 & $897(81.5)$ & & & 935 (84.9) & & \\
\hline On-pump & 121 & $98(81.0)$ & & & $100(82.7)$ & & \\
\hline Off-pump & 378 & 264 (69.8) & & & 287 (75.9) & & \\
\hline
\end{tabular}

*, off-pump as reference. Adjusted for age, sex, medical history of hypertension, diabetes and hyperlipidemia, SYNTAX score, target vessel distribution, antiplatelet therapy and statin use. CABG, coronary artery bypass grafting; Cl, confidence interval; OR, odds ratio.

Table S5 Cardiovascular events between patients receiving on-pump and off-pump CABG

\begin{tabular}{lcc}
\hline Events & On-pump $(\mathrm{N}=121)(\%)$ & Off-pump (N=379) (\%) \\
\hline MACE in 1 year & $5(4.1)$ & $11(2.9)$ \\
CV death & $1(0.8)$ & $2(0.5)$ \\
Nonfatal MI & $4(3.3)$ & $3(0.8)$ \\
Nonfatal stroke & $0(0.0)$ & $6(1.6)$ \\
Recurrent angina in 1 year & $3(2.5)$ & $30(7.9)$ \\
\hline
\end{tabular}

CABG, coronary artery bypass grafting; CV, cardiovascular; MACE, major adverse cardiovascular event; MI, myocardial infarction.

Table S6 Patients with bleeding events between on-pump and off-pump CABG

\begin{tabular}{|c|c|c|c|}
\hline Event categories & On-pump (N=121) (\%) & Off-pump (N=379) (\%) & $P$ value \\
\hline Non-CABG-related & $9(7.4)$ & 77 (20.3) & 0.001 \\
\hline Major & $0(0.0)$ & $3(0.8)$ & 1.000 \\
\hline Minor & $1(0.8)$ & $3(0.8)$ & 1.000 \\
\hline *Overall major bleeding & $1(0.8)$ & $4(1.1)$ & 1.000 \\
\hline
\end{tabular}

*, overall major bleeding includes CABG-related bleeding and non-CABG-related major bleeding. CABG, coronary artery bypass grafting. 
Table S7 Other adverse events by on-pump CABG and off-pump CABG subgroups

\begin{tabular}{|c|c|c|c|c|c|c|c|c|c|}
\hline Categories & \multicolumn{2}{|c|}{$T+A$} & \multicolumn{2}{|c|}{$\mathrm{T}$} & \multicolumn{2}{|c|}{ A } & \multicolumn{2}{|c|}{ Total } & ${ }^{*} \mathrm{P}$ value \\
\hline \multicolumn{10}{|c|}{ Renal dysfunction (Cr $>200 \mu \mathrm{mol} / \mathrm{L})$} \\
\hline On-pump & 39 & $3(7.7)$ & 36 & $0(0.0)$ & 46 & $2(4.4)$ & 121 & $5(4.1)$ & 0.273 \\
\hline Off-pump & 129 & $9(7.0)$ & 130 & $9(6.9)$ & 120 & $4(3.3)$ & 379 & $22(5.8)$ & 0.375 \\
\hline On-pump & 39 & $4(10.3)$ & 36 & $6(16.7)$ & 46 & $2(4.4)$ & 121 & $12(9.9)$ & 0.202 \\
\hline Off-pump & 129 & $1(0.8)$ & 130 & $3(2.3)$ & 120 & $1(0.8)$ & 379 & $5(1.3)$ & 0.627 \\
\hline \multicolumn{10}{|c|}{ Pulmonary infectious } \\
\hline On-pump & 39 & $0(0.0)$ & 36 & $0(0.0)$ & 46 & $0(0.0)$ & 121 & $0(0.0)$ & - \\
\hline On-pump & 39 & $2(5.1)$ & 36 & $1(2.8)$ & 46 & $1(2.2)$ & 121 & $4(3.3)$ & 0.829 \\
\hline Off-pump & 129 & $7(5.4)$ & 130 & $5(3.9)$ & 120 & $9(7.5)$ & 379 & $21(5.5)$ & 0.450 \\
\hline
\end{tabular}

*, $P$ value was obtained from the Fisher's exact test. CABG, coronary artery bypass grafting.

Table S8 Other adverse events between patients receiving on-pump and off-pump CABG

\begin{tabular}{|c|c|c|c|}
\hline Event categories & On-pump ( $\mathrm{N}=121)(\%)$ & Off-pump (N=379) (\%) & $P$ value \\
\hline Liver dysfunction (ALT/AST >320/200 U/L) & $12(9.9)$ & $5(1.3)$ & $<0.001^{*}$ \\
\hline Pulmonary infectious & $0(0.00)$ & $6(1.6)$ & $0.344^{*}$ \\
\hline Delayed incision healing & $4(3.3)$ & $21(5.5)$ & 0.326 \\
\hline
\end{tabular}

*, $P$ value was obtained from Fisher's exact test. CABG, coronary artery bypass grafting; SAE, serious adverse event. 